\title{
Improving the accuracy of estimating paper permanence for accelerated degradation in closed vials
}

\author{
Myung-Joon Jeong $\cdot$ Antje Potthast $\mathbb{1}$
}

Received: 29 September 2020/Accepted: 3 March 2021 / Published online: 20 March 2021

(C) The Author(s) 2021

\begin{abstract}
To more accurately predict the permanence of paper during natural aging, we studied cellulose aging according to closed vial setup, which compared to alternative paper aging methods is closer to natural aging with regard to predictions of paper life expectancy. To improve kinetic evaluation, not only cellulose degradation by hydrolysis and oxidation, but also the moisture content in the closed vial were measured during the aging process. This allowed to eliminate the long-known errors of the method caused by vial leakage which falsely produce different aging rates for different aging periods. With the aim of predicting paper permanence more accurately, several ways of considering the moisture changes and the influences of paper moisture and vial leakage were considered and an improved protocol was elaborated that corrects the rate of cellulose chain scission based on the average moisture content in the paper. Based on this hydrolysis rate, the expected half-life DP becomes independent of the aging period and thus less errorprone and more reliable. We hope that this
\end{abstract}

M.-J. Jeong

Department of Wood Science and Technology, Jeonbuk National University, Jeonju 54896, Korea

A. Potthast $(\square)$

Department of Chemistry, Institute of Chemistry of Renewable Resources, University of Natural Resources and Life Sciences, Konrad-Lorenz-Strasse 24, 3430 Tulln, Austria

e-mail: antje.potthast@boku.ac.at improvement of the very common closed-vial aging method will quickly be accepted and welcomed by the paper conservation community.

Keywords Accelerated degradation - Cellulose · Cellulose hydrolysis · Paper - Paper conservation . Half-life DP

\section{Introduction}

Since the invention of papermaking cellulose paper has been one of the most important recording media used to communicate, record information and disseminate knowledge in written form.Paper is actually far from being an everlasting medium. The non-permanence of - in many cases valuable and rare-paper materials, or in other words their aging and degradation, remains a key problem of libraries, museums and exhibitions worldwide and is one of the main activity fields in conservation science. Countless paper records published centuries or millennia ago have been well preserved until the present day, others were less fortunate and suffered rather severe deterioration. Conservators and collection managers have a responsibility to maintain these records in the best condition possible in order to hand them down to future generations. 
In addition to damage caused by perusal, cellulosic paper is stressed by a wide range of factors, including thermal energy, moisture, irradiation, microorganisms, and air pollutants (Stamm 1956; Arney and Jacobs 1979; Banik and Brückle 2011; Sequeira et al. 2014; Fenech et al. 2010; Becker et al. 2016; Feber et al. 1998, Potthast et al. 2008; Havermans 1995) which all contribute to the overall cellulose aging. This aging, although rather ill-defined as a term and monitored according to widely varying parameters and methods, mechanical and chemical tests, can be traced down at the molecular level to two processes, cellulose hydrolysis and/or cellulose oxidation. Conservation attempts naturally aim at minimizing the effects of aging which, at first, requires accurate methods for detecting and the molecular bases of cellulose degradation and for quantifying their extent (Henniges et al. 2006). This also entails methods for accelerated degradation that should mimic natural aging as closely as possible, because waiting for the effects of natural aging to occur is evidently impractical.

To protect especially valuable cellulosic papers that are part of our cultural heritage from such risk factors, they are-ideally-stored under controlled conditions, at controlled temperature and humidity, with air being supplied in purified form through filters in spite of limited effectiveness (Menart et al. 2014, Ligterink and di Pietro 2018), and light being blocked completely or at least in its higher-energy range (UV). In spite of all advances in the quality of storage environments, cellulose paper undergoes an inevitable, progressive degradation over time due to hydrolysis and oxidation (Area and Cheradame 2011; Henniges et al. 2006; Zervos 2010). For this reason, conservators in archives and museums keep being interested in optimum storage environments, and life expectancy of historic paper to adjust storage and conservational measures accordingly considering the balance between preserving the collection and energy investments (Coppola et al. 2020).

To predict the life expectancy of cellulosic papers, it is important to measure changes of the paper properties after artificial (accelerated) paper aging. The main parameters that have been examined are changes in mechanical strength, such as folding endurance, tensile strength, and stiffness; optical properties, such as the ISO brightness or color change; $\mathrm{pH}$; the degree of polymerization (DP) of cellulose; and oxidation (Kaminska et al. 2001, Hwang and Jeong 2019, Jeong et al. 2014a, Strlič et al. 2004, Potthast et al. 2008). While mechanical tests only respond when cellulose damage is already relatively advanced (Tétreault et al. 2019; Son et al. 2017; Strlič et al. 2015; Zou et al. 1994), molecular parameters (DP, oxidation degree, chromophores) are much more sensitive and show incipient damage also when mechanical performance is still unaffected.

With regard to artificial aging, numerous accelerated degradation methods have been proposed, which typically use a climate chamber to simulate rather extreme conditions in terms of temperature and humidity, UV light, or chemicals (Arney and Jacobs 1979; Jeong et al. 2014b; Menart et al. 2011, 2014; Son et al. 2017; Choi et al. 2019). However, despite the optimization of metrics and conditions for accelerating aging, there remain differences between natural and accelerated degradation due to the harshness of the conditions during the latter aging mode and the role of degradation byproducts (volatiles) originating from the paper during the accelerated degradation. To reduce these methodological differences and better approximate natural storage, it was proposed that accelerated paper aging should take place in closed systems, such as in a closed reaction vessel (Sawoszczuk et al. 2008; TAPPI T573 2015; Zou et al. 1996a; Kaminska et al. 2001; Shahani et al. 2001; Jeong et al. 2012). This method is not only more economical than the traditional method using a climate chamber, but likely approximates the natural aging that occurs at room temperature: the paper degradation products generated by the paper itself are not removed and may interact with the paper in the sealed environment. (Menart et al. 2014; Shahani et al. 2001; Strlič et al 2010; Tétreault et al. 2013; Becker et al. 2016). In addition, this aging method can investigate the effects of special atmospheres or specific pollutants by introducing chemicals into the closed vessel (Strlič et al. 2011), unlike the aging methods involving flow-through reaction vessels or aging chambers. Despite these advantages that have rendered it a standard aging approach used worldwide today, the method has a significant drawback: the difficulty of accurately assessing the cellulose degradation kinetics due to the continuous, nearly unavoidable leakage of moisture and gaseous substances from the vessel during aging (Sawoszczuk et al. 2008). Such leakage interferes with the cellulose degradation and 
significantly influences the degradation rate (kinetics) during the aging period, making the resulting lifeexpectancy values rather error-prone (Kaminska et al. 2001; Sawoszczuk et al. 2008; Shahani et al. 2001).

To improve the method and increase the accuracy with which the degradation kinetics of cellulosic papers in a closed vessel can be evaluated, this study evaluated the amount of moisture leakage during aging with the aim of correcting the cellulose hydrolysis rate. The hydrolysis rate and oxidation rate of cellulose paper during accelerated degradation reflect the rate of cellulose degradation. For cellulose hydrolysis, the rate of cellulose chain scissionswhich can directly affect the mechanical properties of paper in later stages, was evaluated based on changes in DP, which in turn are based on the changes of the weightaverage molar mass during accelerated degradation. For cellulose oxidation, the carbonyl group content, which is a key indicator of oxidative degradation, was analyzed (Potthast et al. 2003). The ultimate goal of the study was to improve the closed-vial method for accelerated degradation, in order to provide a more accurate evaluation of the permanence of cellulose paper, in particular the time required for the cellulose in the paper to reach 50\% loss of DP (half-life DP), which is most commonly used parameter to reflect the expected shelf-life of such cellulosic paper matrices.

\section{Materials and methods}

\section{Materials}

Filter paper Whatman No. 1 (alpha cellulose content $\geq 98 \%, 46 \times 57 \mathrm{~cm}^{2}$ ) was selected as the cellulose paper for accelerated degradation, and a bleached chemical pulp (Encell, eucalyptus pulp, (EN)), Historic rag paper (paper 1 in Becker et al. 2016) and an acidic book paper (printed 1968) were compared. For aging in a closed reaction vial, $100 \mathrm{ml}$ Duran ${ }^{\circledR}$ GL 45 Premium bottles (actual volume: $134.5 \pm 0.3 \mathrm{ml}$ ) with a PBT (polybutylene terephthalate) cap (PTFE (polytetrafluorethylene)-coated silicone seal, temperature resistant to $+180{ }^{\circ} \mathrm{C}$ ) was used. A DS1923 temperature/humidity logger (iButton ${ }^{\circledR}$ ) with $8 \mathrm{~KB}$ data-log memory (size: $5.89 \mathrm{~mm} \times 17.35 \mathrm{~mm}$, operating range from $-20{ }^{\circ} \mathrm{C}$ to $+85^{\circ} \mathrm{C} ; 0$ to $100 \% \mathrm{RH}$ ) was used to record temperature and relative humidity (RH) once every hour over the entire period for pre- conditioning, accelerated degradation except for $100{ }^{\circ} \mathrm{C}$ and post-conditioning at room temperature.

The chemicals used were of the highest purity grade available. The solvents were of HPLC grade, and the reagents were of p.a. (pro analysi) grade. Carbazole-9carbonyloxy amine (CCOA) for selective fluorescence labeling of carbonyl groups in cellulose was synthesized according to literature (Röhrling et al. 2001; 2002).

Procedure for preconditioning and accelerated degradation

$374 \pm 2 \mathrm{mg}$ of an oven-dry paper sample was placed in the vial, which is one-tenth of the amount conventionally used in a closed vial. The smaller amount was used to accelerate changes in moisture content caused by moisture leakage during aging. Six of the vials were equipped additionally with a DS1923 iButton (Maxim Integrated Products, Ltd.) to record temperature and $\mathrm{RH}$ in the closed vial. Each vial was preconditioned in a glove box $\left(20{ }^{\circ} \mathrm{C}\right.$, RH $\left.54.4 \% \pm 0.4\right)$ for at least $24 \mathrm{~h}$, after which it was sealed with a PBT cap, at the same time, four of these samples were immediately dried at $105{ }^{\circ} \mathrm{C}$ to constant weight to measure their moisture content. Accelerated degradation was carried out at four different temperatures: $100{ }^{\circ} \mathrm{C}$ for 2 and 5 days, $80{ }^{\circ} \mathrm{C}$ for 17 and 46 days, $65^{\circ} \mathrm{C}$ for 85 and 210 days, and $50{ }^{\circ} \mathrm{C}$ for 180 and 385 days in dry heat oven. After accelerated degradation, the samples were conditioned for one day at room temperature (20-23 ${ }^{\circ} \mathrm{C}$ ) without opening the vial in order to reach equilibrium moisture content. Then four samples for each aging condition were quickly transferred to a weighing bottle as soon as they were opened, and the weight of the samples was measured. These samples were then dried at $105^{\circ} \mathrm{C}$ to constant weight to calculate their moisture content.

Fluorescence labeling of carbonyl groups and cellulose dissolution

CCOA labeling of carbonyl groups was performed according to Röhrling et al. (2002). Briefly, $25 \mathrm{mg}$ of oven-dry pulp samples were agitated with water in a mixer for $30 \mathrm{~s}$ and the water was removed by filtration under reduced pressure. Each sample was stirred in $4 \mathrm{~mL}$ of $20 \mathrm{mM}$ zinc acetate buffer $(\mathrm{pH} \mathrm{4.0)}$ with $5.0 \mathrm{mg}$ of CCOA and agitated in a water bath at $40{ }^{\circ} \mathrm{C}$ 
for 7 days. After the CCOA labeling, samples were separated by filtration, thoroughly washed, and subsequently activated with DMAc for one day after solvent exchange (Potthast et al. 2015). The DMAcactivated samples were dissolved in $2 \mathrm{~mL}$ of DMAc/ $\mathrm{LiCl}(9 \%, \mathrm{w} / \mathrm{v})$ at room temperature for two days. The solution was then diluted with pure DMAc and filtrated through a $0.45 \mu \mathrm{m}$ filter before injection into the gel permeation chromatography (GPC) system.

\section{Molar mass and degree of oxidation}

Evaluation of cellulose paper degradation was carried out by measuring molar mass and carbonyl (keto group/aldehyde) content by GPC with multi-angle light scattering (MALLS; Wyatt Dawn DSP), refractive index (Shodex RI-71), and fluorescence detection (TSP FL2000, $290 \mathrm{~nm}$ excitation, $340 \mathrm{~nm}$ emission). $\mathrm{DMAc} / \mathrm{LiCl}(0.9 \%, \mathrm{w} / \mathrm{v})$ filtrated through a $0.02 \mu \mathrm{m}$ filter was used as the eluant. The sample was injected automatically and chromatographed on four serial SEC columns (PLgel MIXED A-LS, $20 \mu \mathrm{m}$, $7.5 \times 300 \mathrm{~mm})$. A refractive index increment of $0.136 \mathrm{~mL} / \mathrm{g}$ for cellulose in DMAc/ $\mathrm{LiCl}(0.9 \% \mathrm{w} / \mathrm{v})$ at $25{ }^{\circ} \mathrm{C}$ and $\lambda=488 \mathrm{~nm}$ was used. Molar mass distribution and other polymer-relevant parameters were calculated using the ASTRA and GRAMS software programs. Purely hydrolytic degradation of cellulose generates only novel reducing end-groups (REGs) while oxidation introduces additional alongchain carbonyl group. REGs were obtained from the number-average molar mass $(\mathrm{g} / \mathrm{mol})$, and the alongchain carbonyl content (without reducing ends) was calculated as the difference between measured total carbonyl content and REGs.

Evaluation of accelerated temperature testing of cellulose paper

Based on the obtained molar mass data, the kinetic rate of cellulose chain scissions was calculated by the Ekenstam Eq. (1). DP values were calculated from the weight-average molar mass. To extrapolate the rate of cellulose chain scission to room temperature, the Arrhenius Eq. (2) was applied. $k t=\frac{1}{D P_{t}}-\frac{1}{D P_{0}}$

$k$, rate of cellulose chain scission; $t$, aging time (day); $D P_{0}$, initial DP before accelerated degradation; $D P_{t}$, DP of aged paper at time $t$

$k=A e^{-\frac{E}{R T}} \quad\left(\ln \mathrm{k}=\ln \mathrm{A}-\frac{E}{R T}\right)$

$A$, Arrhenius pre-exponential (frequency) factor; $E$, activation energy (kJ/mol); $R$, universal gas constant; $T$, absolute temperature (K).

The Arrhenius pre-exponential factor, $A$, was obtained by linear regression from the logarithmic form of Eq. (2). The time to reach the half-life DP $\left(t_{H}\right)$ at room temperature was obtained from the rate of cellulose chain scission, $k$, at $21^{\circ} \mathrm{C}$. This was extrapolated from the Arrhenius equation as follows (3):

$t_{H}=\frac{\frac{1}{\left(D P_{0} / 2\right)}-\frac{1}{D P_{0}}}{k}=\frac{1}{D P_{0} k}$

$t_{H}$, the time to reach the half-life DP; $D P_{0}$, initial DP before accelerated degradation.

\section{Results and discussion}

\section{Prediction of half-life DP}

The Arrhenius plot of the rate of degradation shows the correlation between aging temperature and the hydrolysis rate expressed as chain scissions (Fig. 1). Plots were generated from two different aging periods. The obtained activation energies for the short- and long-term aging periods were $98.51 \pm 0.01$ and $99.97 \pm 0.04 \mathrm{~kJ} / \mathrm{mol}$, respectively. The Arrhenius plot of accelerated degradation for the short-term period $\left(\mathrm{R}^{2}=0.9852\right)$ showed almost perfect linearity and was closer to 1.0 than that for the long-term aging $\left(\mathrm{R}^{2}=0.9861\right)$. The differences in the hydrolysis rate between the short- and long-term aging periods translates into different extrapolated times at which the half-life DP is reached: 222 and 558 years, respectively, a difference of around 2.5 times (Fig. 1 bottom). The predicted time for half-DP increased with prolonged aging time. Our hypothesis is, that this difference was mainly caused by the decreasing 

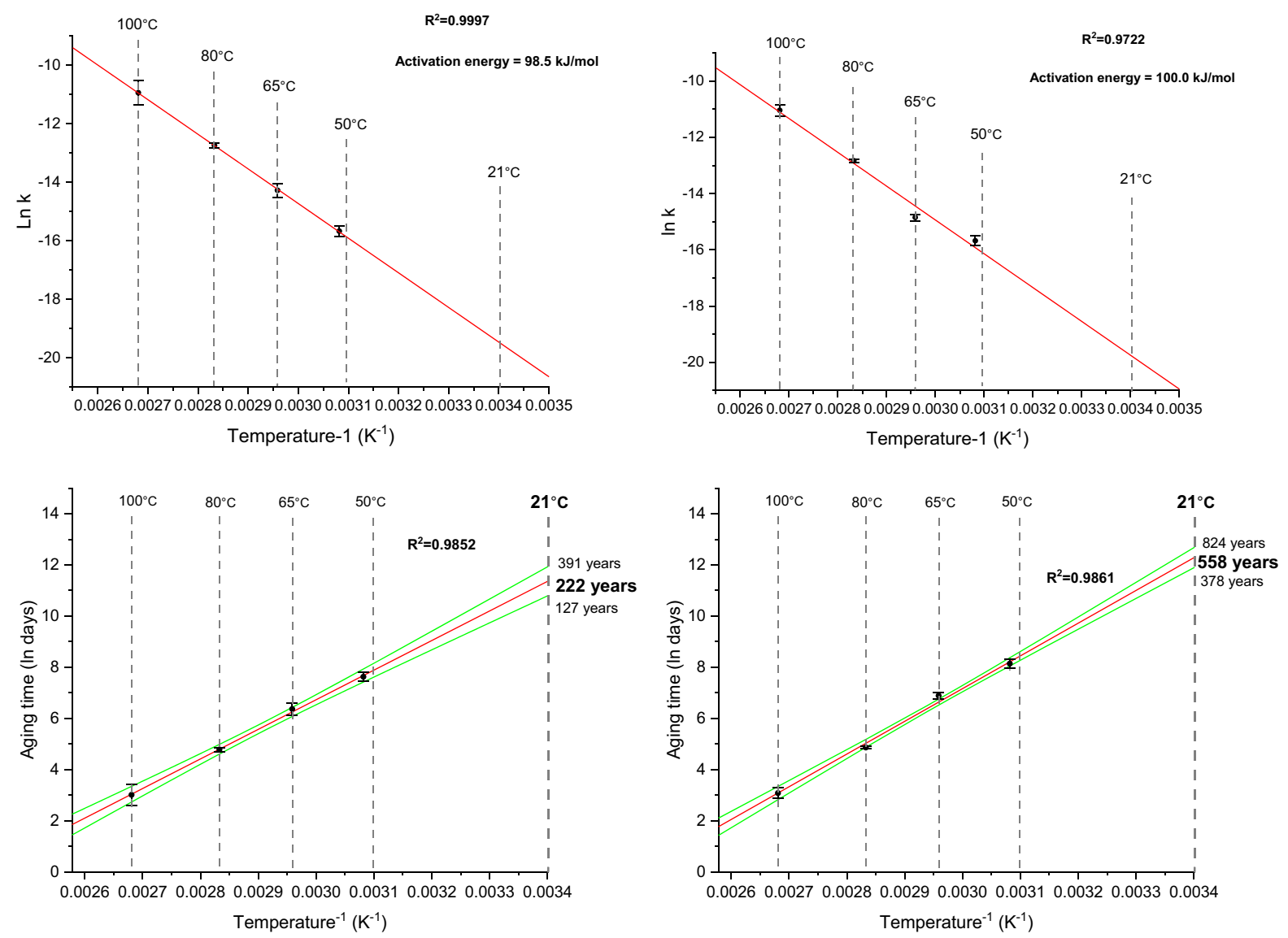

Fig. 1 Top: Arrhenius plot of the rate of cellulose chain scission of Whatman No. 1 by aging temperature and time. Left: Period I (short-term period: 2 days, $100{ }^{\circ} \mathrm{C} ; 17$ days, $80^{\circ} \mathrm{C} ; 85$ days, $65^{\circ} \mathrm{C}$; and 180 days, $50{ }^{\circ} \mathrm{C}$ ). Right: Period II (long-term period:

moisture content in the closed vial due to continuous leakage during aging. To obtain a more reliable estimate of half-life DPs and times, it is necessary to consider the reduction in moisture that occurs in the vial during aging.

\section{Consideration of changes in relative humidity}

The aging rate of paper $\left(k_{1}, k_{2}\right)$ is affected not only by temperature but also by the relative humidity $\mathrm{RH}$ (Sebera 1994; Zou et al. 1996a, b; Shahani et al. 2001). Sebera (1994) suggested that there is a direct proportion between the rate of degradation and moisture, as shown in Eq. (4):

$\frac{k_{2}}{k_{1}}=\frac{H_{2} \text { Oconcentration }_{2}}{H_{2} \text { Oconcentration }_{1}}=\frac{R H_{2}}{R H_{1}}$

5 days, $100{ }^{\circ} \mathrm{C} ; 45$ days, $80{ }^{\circ} \mathrm{C} ; 210$ days, $65{ }^{\circ} \mathrm{C} ; 385$ days, $50{ }^{\circ} \mathrm{C}$ ). Bottom: Extrapolated times to reach the half-life DP of Whatman No. 1 at room temperature $\left(21^{\circ} \mathrm{C}\right)$. Left: period I. Right: period II (cf. figure). Confidence interval: $95 \%$

This appears to be a reasonable proposition if we assume that water participates as one reactant in the rate-determining step of the hydrolysis and thus becomes a direct factor in the kinetic rate law. However, this is only valid when a closed system is given, and hence the paper is maintained under constant temperature and humidity during aging in a climate chamber. In reality, leakage of vapor occurs when closed-vial aging takes place at elevated temperatures. Although the vials used have usually caps of the highest quality available, as it was also the case in our experiments, they are not made for longterm, high temperature stability. Hence, at longer aging times there will always be a small leakage, i.e. a minor loss of moisture, which cannot be prevented at elevated temperatures. However, the effect is sufficient to significantly influence the kinetics (note that 
from those aging kinetics the half-lives are extrapolated so that possible errors will potentiate)-a significant drawback for the accuracy of aging kinetic studies. It should be mentioned that in such studies the use of sealants is forbidden due to their unknown aging chemistry and influence on the system. This leakage eventually interferes with the results, specifically those regarding the relationship between the hydrolysis rate of cellulose and moisture content in the closed vial. The initial moisture content in the vial will continuously decrease as aging proceeds. Therefore, it is necessary to modify the cellulose hydrolysis rate $(k)$ to take the decrease in moisture content caused by leakage into account.

Changes in the moisture in the closed vial, i.e. $\mathrm{RH}$, were evaluated from the RH data obtained by a temperature/humidity logger (iButton). Figure 2 shows the changes in $\mathrm{RH}$ inside the closed vial recorded by the iButton sensor in relation to aging temperature. After aging at 80,65 , and $50{ }^{\circ} \mathrm{C}$ for different periods, $\mathrm{RH}$ decreased by around $9 \%, 27 \%$, and $36 \%$, respectively, based on the initial $\mathrm{RH}$ value. The RH change in the vial depended on the initial RH, aging temperature, and aging period. It can be simply expressed by Eq. 5 .

Relative humidity $(\mathrm{RH}, \%)=R H_{0} \cdot e^{C \cdot n}$

$\mathrm{RH}_{0}$, initial $\mathrm{RH}(\%)$ at each temperature $\left(51.5^{\circ} \mathrm{C}\right.$ : 47.1\%; $65.0{ }^{\circ} \mathrm{C}: 36.1 \%$; $\left.80.0{ }^{\circ} \mathrm{C}: 28.5 \%\right)$; $C$, leakage constant related to the vial caps' sealability at each temperature $\left(51.5^{\circ} \mathrm{C}:-0.0084 ; 65.0^{\circ} \mathrm{C}:-0.0187\right.$; $80.0{ }^{\circ} \mathrm{C}$ : -0.0280 ); $n$, aging time (days).

For an aging experiment lasting up to 385 days, as was the case in the present study, it is impractical, if not nearly impossible, to determine the $k$ values every day or even in shorter intervals as a GPC measurement would be required, while measuring $\mathrm{RH}$ by means of the internal recording devices was easy. In the next step, we thus tried to correct the $k$ value using the average $\mathrm{RH}$ value for the measurement period. First, the average $\mathrm{RH}\left(\mathrm{RH}_{A v}\right)$ during the aging period was calculated by Eq. (6):

Average relative humidity $\left(R H_{A v}\right)=\left(\sum_{\mathrm{i}=1}^{n} \mathrm{RH}_{i}\right) / \mathrm{n}$

$n$, number of data acquisitions from the temperature/ humidity logger during the aging period.

Based on Sebera's equation which worked only with the initial humidity (Eq. 4), the $k$ value was corrected to $k^{\prime}$ based on the ratio of initial $\mathrm{RH}\left(R H_{0}\right)$ to average RH (Eq. 7):

$k^{\prime}=\mathrm{k} \frac{R H_{0}}{R H_{A v}} \quad\left(\frac{k_{t}}{k_{t}^{\prime}}=\frac{R H_{A v}}{R H_{0}}\right)$

$k$, the rate of cellulose chain scission before correction; $k^{\prime}$, the corrected rate of cellulose chain scission; $R H_{A v}$, average relative humidity $(\%) ; R H_{0}$, initial relative humidity (\%).

Table 1 compares the $k^{\prime}$ values corrected for the average $\mathrm{RH}$ with the original $k$ value without correction. When a $k$ value was obtained only based on the initial RH without taking the RH change into account, there was a significant difference between short- and long-term aging (see above). However, when the $k^{\prime}$ value (corrected by using average $\mathrm{RH}$ ) was employed,
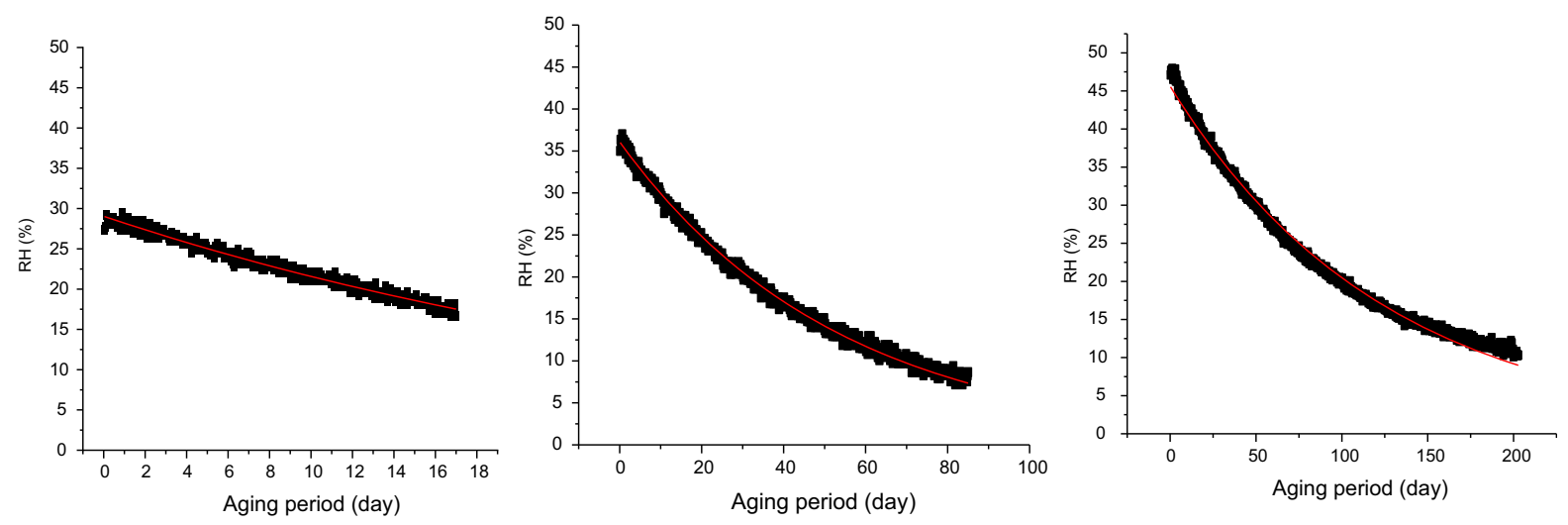

Fig. 2 Change in $\mathrm{RH}$ in relation to aging periods at different aging temperatures (left: $80^{\circ} \mathrm{C}$, middle: $65^{\circ} \mathrm{C}$, right: $50{ }^{\circ} \mathrm{C}$ ) 
Table 1 Relative humidity $(\mathrm{RH})$ and rate of cellulose chain scission before correction $(k)$ and after correction $\left(k^{\prime}\right)$ as a function of aging temperature and period

\begin{tabular}{lllllll}
\hline Aging temperature $\left({ }^{\circ} \mathrm{C}\right)$ & Aging period (days) & & \multicolumn{2}{l}{$\mathrm{RH}^{*}$} & & \multicolumn{2}{l}{ Rate of cellulose chain scission } \\
\cline { 6 - 7 } & & Initial & Average & & $k$ & $k^{\prime}$ \\
\hline 80.0 & 17 & 27.7 & 22.9 & & $2.90 \times 10^{-6}$ & $3.52 \times 10^{-6}$ \\
& 45 & & 17.0 & & $2.68 \times 10^{-6}$ & $4.38 \times 10^{-6}$ \\
65.0 & 85 & 34.7 & 18.0 & & $6.27 \times 10^{-7}$ & $1.21 \times 10^{-6}$ \\
& 210 & & 10.7 & & $3.55 \times 10^{-7}$ & $1.15 \times 10^{-6}$ \\
51.5 & 180 & 47.7 & 22.1 & & $1.56 \times 10^{-7}$ & $3.36 \times 10^{-7}$ \\
& 385 & & 17.2 & & $1.03 \times 10^{-7}$ & $2.87 \times 10^{-7}$ \\
\hline
\end{tabular}

$*$ Standard deviation: $1.36 \%\left(51.5^{\circ} \mathrm{C}\right), 1.64 \%\left(65^{\circ} \mathrm{C}\right), 1.75 \%\left(80{ }^{\circ} \mathrm{C}\right)$

the discrepancy between short- and long-term got much smaller.

But even in the cases where $k^{\prime}$ values improved, a final decrease was inevitable when the DP approached leveling-off DP (LODP), i.e. at fairly long aging times. LODP is generally considered to be a DP of a few hundreds. However, for all aging cases in which the DP is reduced to approx. 2,000 (as also in this study) and is thus still far from approaching the LOPD, the corrected $k^{\prime}$ values represent a distinct improvement, and consideration of the average $\mathrm{RH}$ for correction is definitely of value.

As a result, estimating the half-life DPs using the $k^{\prime}$ value (Fig. 3) resulted in a reduction of the difference between short-term and long-term aging of around $25 \%$ compared with half-life DPs estimated just using $k$ (Fig. 1). However, even after using the corrected $k^{\prime}$ values based on average $\mathrm{RH}$, the resulting half-life
DPs still showed a 19-year difference between shortand long-term aging periods. This is because the changes in the moisture content of paper do not always directly correspond with changes in $\mathrm{RH}$, especially at prolonged aging times which progressively change the internal paper structure, pore systems and accessibility (Banik and Brückle 2010). To evaluate the half-life DP more accurately, it is consequently necessary to directly measure changes in paper moisture content.

Consideration of changes in the papers' moisture content

Hydrolysis of cellulose mainly takes place in amorphous regions where water molecules can access to promote cellulose hydrolysis reactions by acids (Kontturi et al. 2016). Hydrolysis is directly related to the water molecules in the paper itself. This would,
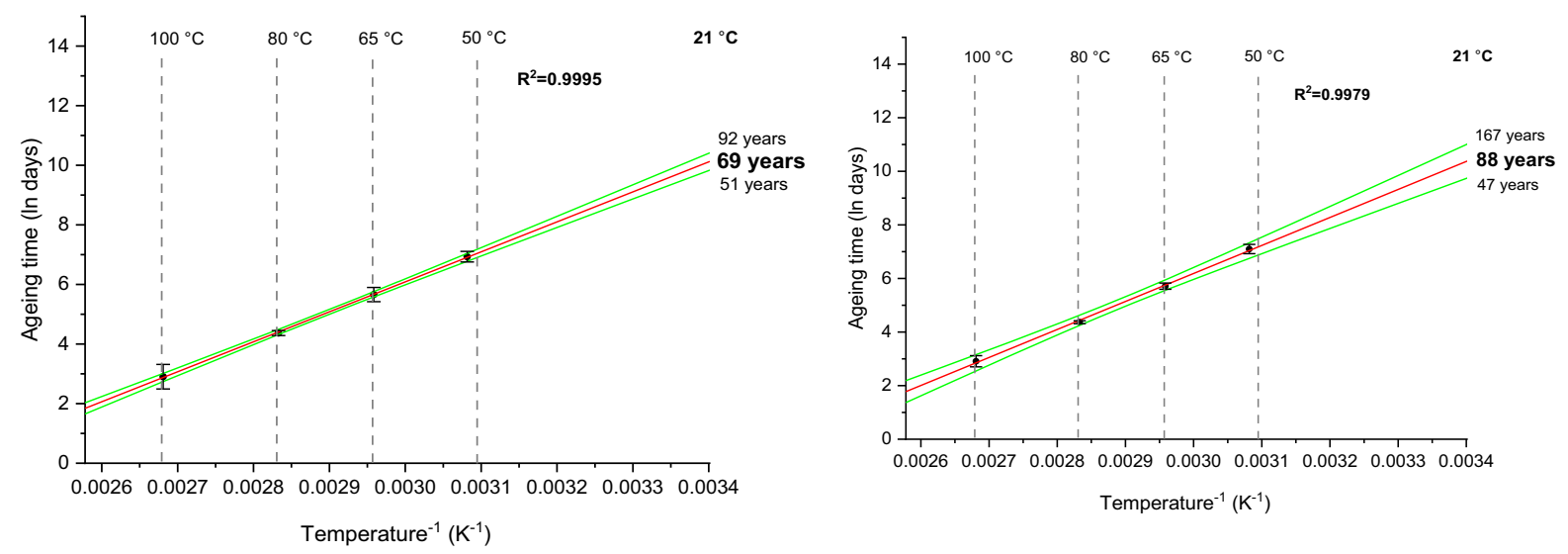

Fig. 3 Extrapolated periods of time required to reach the half-life DP (Whatman No. 1 at room temperature $\left(21^{\circ} \mathrm{C}\right)$ after $k$ correction, left: period I, right: period II). Confidence interval: $95 \%$ 
theoretically, also mean a direct correlation with the moisture in the closed vial in our special case of aging (or the surrounding environment in general)-provided, of course, that the moisture content in the paper is proportional to $\mathrm{RH}$. However, the relationship between moisture content in paper and $\mathrm{RH}$ usually takes the form of a sigmoidal curve rather than that of a perfect line (Banik and Brückle 2010). Hence, for more accurate measurements of the rate of cellulose chain scission and for better half-life extrapolations based on those values, the changes in paper moisture content, and not only in the surrounding medium, also need to be evaluated. Unfortunately, the direct measurement of changes in paper moisture content at elevated temperatures during aging is not viable. For this reason, the changes in moisture content had to be assessed indirectly.

The water vapor content in the void of the vial $\left(M_{v}\right)$ at the elevated aging temperature was calculated using the RH data collected from the temperature/humidity logger (iButton) using Eq. (8):

$M_{v}(\mathrm{mg})=\frac{R H}{100} \times w_{t} \times 0.1345$

$w_{t}$, mass of saturated vapor at each aging temperature (mg/L, $\left.51.5{ }^{\circ} \mathrm{C}: 88.9,65.0^{\circ} \mathrm{C}: 160.5,80.0{ }^{\circ} \mathrm{C}: 290.8\right)$; 0.1345 , volume of aging vial (L). Since the volume occupied by the paper sample in the aging vial was only around 0.0004 (L), it was neglected in the calculation.

The paper moisture content $\left(M_{P}\right)$ was determined using a conventional oven-drying method and calculated based on Eq. (9):

$M_{p}(\%)=\frac{P-P_{O D}}{P} \times 100$

$P$, weight of aged paper sample after aging for a specific period (mg); $P_{O D}$, weight of oven-dried paper sample after aging for a specific period ( $\mathrm{mg}$ ).

In order to accurately measure the paper moisture content, the aged paper sample first needed to be cooled to the same temperature as the electronic balance measurement environment, excluding any moisture exchange or other interactions with the surroundings. Alternatively, the paper moisture content could be estimated at an elevated aging temperature based on the $\mathrm{RH}$ measured at each temperature and the paper moisture content at room temperature using Eq. (10) and (11). The results are summarized in Table 2.

$M_{p_{1}}(m g)=\left(M_{v_{2}}+M_{p_{2}}\right)-M_{v_{1}}$

$M_{v_{1}}$, water vapor content (mg) in the space inside the closed vial at an elevated temperature; $M_{p_{1}}$, moisture content (mg) of the paper sample in the closed vial at an elevated temperature; $M_{v_{2}}$, water vapor content (mg) in the space inside the closed vial at room temperature after cooling; $M_{p_{2}}$, moisture content (mg) of the paper sample in the closed vial at room temperature after cooling

Moisture content at elevated temperature $\left(\%, M_{p_{1}}\right)$

$$
=\frac{M_{p_{1}}}{P_{O D}+M_{p_{1}}} \times 100
$$

$P_{O D}$, oven-dried paper weight $(\mathrm{mg})$.

Changes in the paper moisture content in relation to aging time and temperature can be expressed by Eq. (12). Using this equation and the results shown in Table 2, we estimated the moisture content $(\%, \mathrm{M})$ at specific aging temperatures and aging periods. Changes in moisture content during aging were influenced not only by aging temperature and aging time but also by the initial moisture content at a specific aging temperature. Therefore, at least in the case of Whatman paper as a frequently used model, changes in the paper's moisture content over the aging period can be assessed simply by measuring the moisture content before and after aging without the additional requirement to measure $\mathrm{RH}$.

Moisture content $(\%, \mathrm{M})=M_{0}+\Delta M \cdot e^{c \cdot n}$

$$
\left(\Delta M=M_{1}-M_{0}\right)
$$

$M_{0}$, minimum paper moisture content $(\%)$ at a given aging temperature $\left(\%, 51.5^{\circ} \mathrm{C}: 1.46 \%, 65.0{ }^{\circ} \mathrm{C}\right.$ : $\left.0.71 \%, 80.0{ }^{\circ} \mathrm{C}: 0.32 \%\right) ; M_{1}$, initial moisture content $(\%)$ in paper after reaching the elevated aging temperature; $\Delta M$, maximum variation in moisture content (\%) during the aging period at the elevated aging temperature; $C$, leakage constant related to the vial cap's sealability at each elevated temperature $\left(51.5{ }^{\circ} \mathrm{C}:-0.0103,65.0{ }^{\circ} \mathrm{C}:-0.0233,80.0{ }^{\circ} \mathrm{C}\right.$ : $-0.0135) ; n$, aging time (days). 
Table 2 Moisture content $(\mathrm{mg}, \%)$ in paper and $\mathrm{RH}$ in the closed vial as a function of aging temperature and period

\begin{tabular}{|c|c|c|c|c|c|c|c|}
\hline \multirow[t]{2}{*}{ Aging temperature $\left({ }^{\circ} \mathrm{C}\right)$} & \multirow[t]{2}{*}{ Aging period (day) } & \multicolumn{2}{|c|}{$\begin{array}{l}\text { Aging/cooling } \\
\text { temperature }\left({ }^{\circ} \mathrm{C}\right)\end{array}$} & \multirow[t]{2}{*}{$\mathrm{RH}(\%)$} & \multirow{2}{*}{$\begin{array}{l}\text { Water vapor content inside vial } \\
\mathrm{Mg}\end{array}$} & \multicolumn{2}{|c|}{$\begin{array}{l}\text { Paper moisture } \\
\text { content }\end{array}$} \\
\hline & & & & & & $\mathrm{mg}$ & $\%$ \\
\hline \multirow{8}{*}{$\begin{array}{l}\text { Conditioning } \\
51.5\end{array}$} & & & 20 & 54.4 & 1.27 & 23.49 & 5.91 \\
\hline & 0 & - & 51.5 & 47.1 & 5.66 & 19.10 & 4.81 \\
\hline & 30 & Aging & 51.5 & 25.5 & 3.06 & 15.46 & 3.93 \\
\hline & & Cooling & 22 & 50.6 & 1.32 & 17.20 & 4.35 \\
\hline & 180 & Aging & 51.5 & 10.3 & 1.24 & 7.52 & 1.95 \\
\hline & & Cooling & 21 & 26.8 & 0.66 & 8.10 & 2.10 \\
\hline & 385 & Aging & 51.5 & 5.8 & 0.69 & 6.26 & 1.63 \\
\hline & & Cooling & 21 & 5.9 & 0.14 & 6.81 & 1.77 \\
\hline \multirow[t]{7}{*}{65} & 0 & - & 65 & 36.1 & 7.79 & 16.96 & 4.30 \\
\hline & 20 & Aging & 65 & 25.1 & 5.42 & 11.04 & 2.84 \\
\hline & & Cooling & 23 & 36.2 & 1.00 & 15.45 & 3.93 \\
\hline & 85 & Aging & 65 & 8.1 & 1.74 & 4.86 & 1.27 \\
\hline & & Cooling & 20 & 9.5 & 0.22 & 6.38 & 1.66 \\
\hline & 210 & Aging & 65 & 2.5 & 0.53 & 3.64 & 0.95 \\
\hline & & Cooling & 20 & 2.6 & 0.06 & 4.11 & 1.08 \\
\hline \multirow[t]{7}{*}{80} & 0 & - & 80 & 28.5 & 11.15 & 13.60 & 3.47 \\
\hline & 5 & Aging & 80 & 25.5 & 9.97 & 11.14 & 2.87 \\
\hline & & Cooling & 22 & 50.7 & 1.32 & 19.79 & 4.98 \\
\hline & 17 & Aging & 80 & 17.7 & 6.93 & 10.44 & 2.69 \\
\hline & & Cooling & 22 & 38.9 & 1.02 & 16.36 & 4.15 \\
\hline & 27 & Aging & 80 & 14.5 & 5.66 & 9.46 & 2.44 \\
\hline & & Cooling & 22 & 31.8 & 0.83 & 14.29 & 3.64 \\
\hline
\end{tabular}

The paper moisture content $\left(\mathrm{mg}, \mathrm{M}_{\mathrm{p}_{1}}\right)$ at an elevated aging temperature can be expressed by Eq. (13):

$M_{p_{1}}(m g)=\left(P_{O D} \times M\right) /(100-M)$

$P_{O D}$, oven-dried paper sample weight $(\mathrm{mg})$.

The total moisture content $\left(\mathrm{M}_{\mathrm{t}}\right)$ in the vial can be calculated using Eq. (14) with the calculated moisture shown in Fig. 4:

Total moisture content $\left(\mathrm{mg}, M_{t}\right)=M_{p_{1}}+M_{v_{1}}$

$M_{p_{1}}$, paper moisture content $(\mathrm{mg})$ in the vial at a specific elevated temperature and for a specific aging period; $M_{v_{1}}$, water vapor content $(\mathrm{mg})$ in the space inside the vial at a specific elevated temperature and for a specific aging period.

Based on the moisture variation curves in Fig. 4, changes in paper moisture content and water vapor content in the space inside the closed vial clearly did not show the same pattern as RH over the aging period. This difference between the changes in paper moisture content and water vapor content explains why there was still an error in the estimation of half-life DP between the short- and long-term aging periods when modified $k^{\prime}$ values and average RH were used.

To overcome the limitations of the $k$-correction based on average $\mathrm{RH}\left(R H_{A v}\right)$, the hydrolysis rate was corrected using the average moisture content. Although the average water content does not completely correctly reflect the changes in moisture content during aging, it was estimated that the average moisture content would reduce the error more than by applying average $\mathrm{RH}$. The average moisture content in the aging vessel $\left(M_{A v}\right)$ was calculated using Eq. (15): 

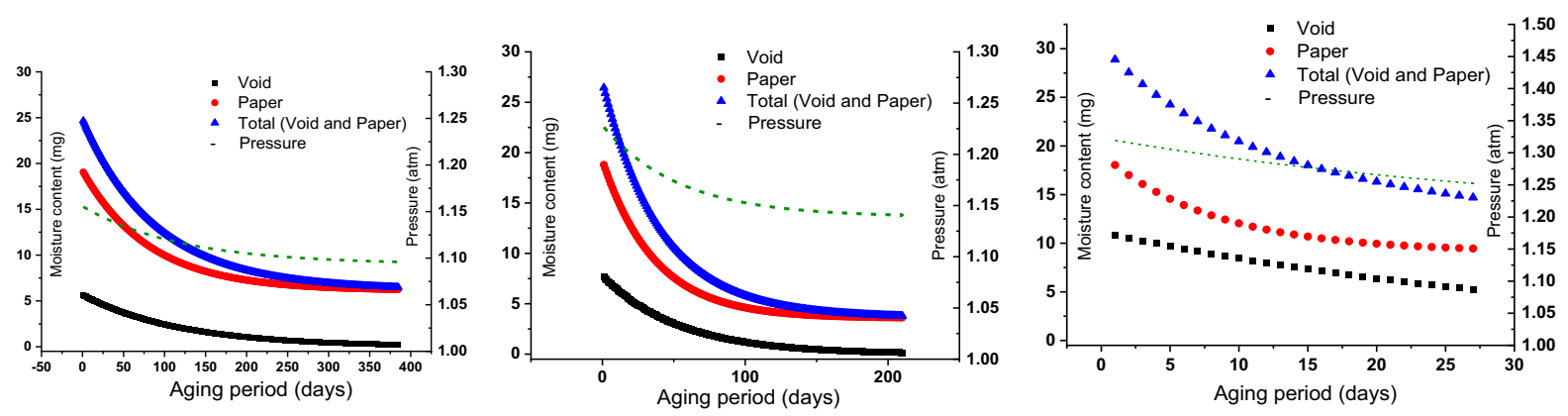

Fig. 4 Calculated moisture content according to temperature and aging period (left: $51.5^{\circ} \mathrm{C}$, middle: $65^{\circ} \mathrm{C}$, right: $80{ }^{\circ} \mathrm{C}$ ). Pressure change is calculated for illustration only based on the given conditions, it does not reflect the actual pressure

Average moisture content $\left(\mathrm{mg}, M_{A v}\right)=\sum_{\mathrm{i}=1}^{n} \mathrm{M}_{T_{i}} / \mathrm{n}$

$$
=\left(\sum_{\mathrm{i}=1}^{\mathrm{n}} M_{p_{i}}+\sum_{\mathrm{i}=1}^{\mathrm{n}} M_{v_{i}}\right) / \mathrm{n}
$$

$n$, aging time (days).

Moisture content change induced by hydrolysis

Another consideration is that changes in moisture inside the aging vial are affected not only by moisture leakage but also by hydrolysis, because one water molecule is consumed for each cleaved glycosidic bond. Therefore, it is necessary to calculate the amount of moisture consumed by cellulose hydrolysis. Moisture consumption by hydrolysis $\left(W_{t}\right)$ during aging can be calculated using the hydrolysis rate $\left(k_{t}\right)$ (16):

$W_{t}(m g)=k_{t} \times w \times 18$

$W_{t}$, moisture consumption by cellulose hydrolysis for aging time, $t$ (days); $k_{t}$, rate of cellulose chain scission for aging time, $t$ (days); $w$, cellulose paper sample amount $(\mu \mathrm{mol})$; 18 , molecular weight of water $\left(\mathrm{H}_{2} \mathrm{O}\right)$.

At each aging temperature and time, the amount of water molecules consumed by hydrolysis was calculated based on the hydrolysis rate $\left(k_{t}\right)$ (Table 3 ). Since the amount of water molecules consumed by glycosidic bond cleavage of cellulose accounts for only around $1 / 1000$ of the total amount leaked from the vial (in the range of $\mu \mathrm{g}$ ), it was unnecessary to take this amount into account in subsequent calculations.
Effect of cellulose oxidation at elevated temperatures

In general, paper aging is accompanied not only by hydrolysis but also by oxidation, and this phenomenon is accelerated when paper is exposed to light, air pollutants or elevated temperatures. In the present study, even though the effects of oxidation were not expected to be significant since the accelerated degradation process was carried out without exposure to light or air pollutants, they had to be evaluated to make sure that any unexpected influences are not overlooked. To evaluate oxidation, the content of the carbonyl groups that are commonly produced when paper is oxidized during natural aging was evaluated, which is best determined by GPC and group-selective fluorescence labeling as carbonyl group profile relative to the molecular weight, since other methods are too inaccurate (Röhrling et al. 2002; Potthast et al. 2003, 2005). Taking into account the decrease in molecular weight by hydrolysis, the effects of oxidation were not significant (Table 4). The increase in carbonyl group content was mainly due to the REGs newly produced when the cellulose chain was cleaved upon hydrolysis. This confirmed that the content of along-chain carbonyl groups, which would be due to oxidation, not hydrolysis, did not increase relative to the non-aged sample. Therefore, at least for our aging conditions that excluded other environmental stressors, hydrolysis was the major factor causing degradation of the paper, while oxidation was not significant enough to be considered. 
Table 3 Calculated moisture $\left(\mathrm{H}_{2} \mathrm{O}\right)$ consumption by cellulose hydrolysis in a closed vial during aging

\begin{tabular}{lll}
\hline Aging temperature $\left({ }^{\circ} \mathrm{C}\right)$ & Aging period (days) & $\mathrm{H}_{2} \mathrm{O}$ consumption by hydrolysis $(\mu \mathrm{g})$ \\
\hline $51.5{ }^{\circ} \mathrm{C}$ & 180 & 1.18 \\
& 385 & 1.67 \\
$65{ }^{\circ} \mathrm{C}$ & 85 & 2.24 \\
& 210 & 3.13 \\
$80{ }^{\circ} \mathrm{C}$ & 17 & 2.07 \\
& 45 & 5.06 \\
$100{ }^{\circ} \mathrm{C}$ & 2 & 1.48 \\
& 5 & 3.37
\end{tabular}

Table 4 Molar mass $\left(M_{n}, M_{w}, M_{z}\right)$, total carbonyl group $(\mathrm{C}=\mathrm{O})$, content of Whatman No. 1 as a function of aging temperature and period

\begin{tabular}{llllll}
\hline Aging temperature $\left({ }^{\circ} \mathrm{C}\right)$ & Aging period (day) & $M_{n}(\mathrm{~kg} / \mathrm{mol})$ & $M_{w}(\mathrm{~kg} / \mathrm{mol})$ & $M_{z}(\mathrm{~kg} / \mathrm{mol})$ & $\mathrm{C}=\mathrm{O}(\mu \mathrm{mol} / \mathrm{g})$ \\
\hline Un-aged & 0 & $208.3 \pm 18.0$ & $467.8 \pm 10.3$ & $769.8 \pm 13.0$ & $1.6 \pm 0.15$ \\
100 & 2 & $187.7 \pm 25.8$ & $424.5 \pm 12.8$ & $757.3 \pm 2.4$ & $2.1 \pm 0.07$ \\
& 5 & $171.3 \pm 3.5$ & $379.8 \pm 11.9$ & $678.6 \pm 39.9$ & $3.1 \pm 0.59$ \\
80 & 17 & $197.9 \pm 15.3$ & $409.4 \pm 7.1$ & $744.0 \pm 28.0$ & $2.5 \pm 0.47$ \\
& 45 & $144.8 \pm 12.5$ & $347.0 \pm 4.0$ & $674.8 \pm 51.6$ & $3.5 \pm 0.54$ \\
65 & 85 & $194.5 \pm 11.1$ & $405.4 \pm 7.7$ & $694.7 \pm 7.5$ & $2.3 \pm 0.06$ \\
& 210 & $179.1 \pm 14.6$ & $384.9 \pm 8.2$ & $666.0 \pm 14.8$ & $2.2 \pm 0.07$ \\
51.5 & 180 & $165.8 \pm 5.0$ & $432.8 \pm 11.5$ & $748.2 \pm 9.0$ & $1.8 \pm 0.03$ \\
& 385 & $197.5 \pm 19.0$ & $419.7 \pm 7.4$ & $723.8 \pm 34.7$ & $2.1 \pm 0.63$ \\
\hline
\end{tabular}

Table 5 Leakage amount as a function of aging period and temperature

\begin{tabular}{lllllll}
\hline $\begin{array}{l}\text { Aging } \\
\text { temp. } \\
\left({ }^{\circ} \mathrm{C}\right)\end{array}$ & $\begin{array}{l}\text { Aging } \\
\text { period } \\
(\text { days })\end{array}$ & $\begin{array}{l}\text { Moisture content } \\
\text { after aging }(\mathrm{mg})\end{array}$ & $\begin{array}{l}\text { Moisture } \\
\text { leakage* } \\
(\mathrm{mg})\end{array}$ & $\begin{array}{l}\text { Average } \\
\text { moisture* } \\
(\mathrm{mg})\end{array}$ & $\begin{array}{l}\text { Ratio of average moisture } \\
\text { to initial moisture* }(\%)\end{array}$ & $\begin{array}{l}\text { Ratio of average leakage } \\
\text { to initial moisture* }(\%)\end{array}$ \\
\hline & 0 & & & 24.8 & & 41.5 \\
51.5 & 180 & 8.76 & 15.99 & 14.5 & 58.5 & 87.9 \\
& 385 & 6.95 & 17.80 & 11.0 & 12.1 & 40.7 \\
65.0 & 85 & 6.60 & 18.16 & 14.7 & 59.3 & 64.5 \\
& 210 & 4.17 & 20.59 & 8.8 & 35.5 & 18.1 \\
80.0 & 17 & 17.37 & 7.38 & 20.3 & 81.9 & 35.5 \\
& 45 & 15.12 & 9.64 & 16.0 & 64.5 & 7.4 \\
& 2 & $17.90^{* *}$ & $4.30^{* *}$ & & $92.6^{* * *}$ & 15.1 \\
\hline
\end{tabular}

*Calculated for the entire aging period

**For aging at $100{ }^{\circ} \mathrm{C}$, moisture and reduced moisture were calculated based on the moisture content in paper but without the data recorded by iButton ${ }^{\circledR}\left(\mathrm{DS} 1923\right.$ iButton ${ }^{\circledR}$ operating temperature: $\left.-20{ }^{\circ} \mathrm{C} \sim+85{ }^{\circ} \mathrm{C}\right)$

***The ratio was calculated as the ratio of average paper moisture content ( $5.14 \%$ for 2 days, $4.71 \%$ for 5 days) and initial paper moisture content $(5.55 \%)$ 
Table 6 Rate of cellulose chain scission before correction $(k)$ and after correction $\left(k^{\prime \prime}\right)$ as a function of aging temperature and period

\begin{tabular}{llll}
\hline Aging temperature $\left({ }^{\circ} \mathrm{C}\right)$ & Aging period (day) & \multicolumn{2}{l}{ Rate of cellulose chain scission } \\
\cline { 3 - 4 } & & $k$ & $k^{\prime \prime}$ \\
\hline 100 & 2 & $1.76 \times 10^{-5}$ & $1.90 \times 10^{-5}$ \\
& 5 & $1.60 \times 10^{-5}$ & $1.89 \times 10^{-5}$ \\
80 & 17 & $2.90 \times 10^{-6}$ & $3.54 \times 10^{-6}$ \\
& 45 & $2.68 \times 10^{-6}$ & $4.12 \times 10^{-6}$ \\
65 & 85 & $6.27 \times 10^{-7}$ & $1.06 \times 10^{-6}$ \\
51.5 & 210 & $3.55 \times 10^{-7}$ & $0.99 \times 10^{-6}$ \\
& 180 & $1.56 \times 10^{-7}$ & $2.64 \times 10^{-7}$ \\
& 385 & $1.03 \times 10^{-7}$ & $2.63 \times 10^{-7}$ \\
\hline
\end{tabular}
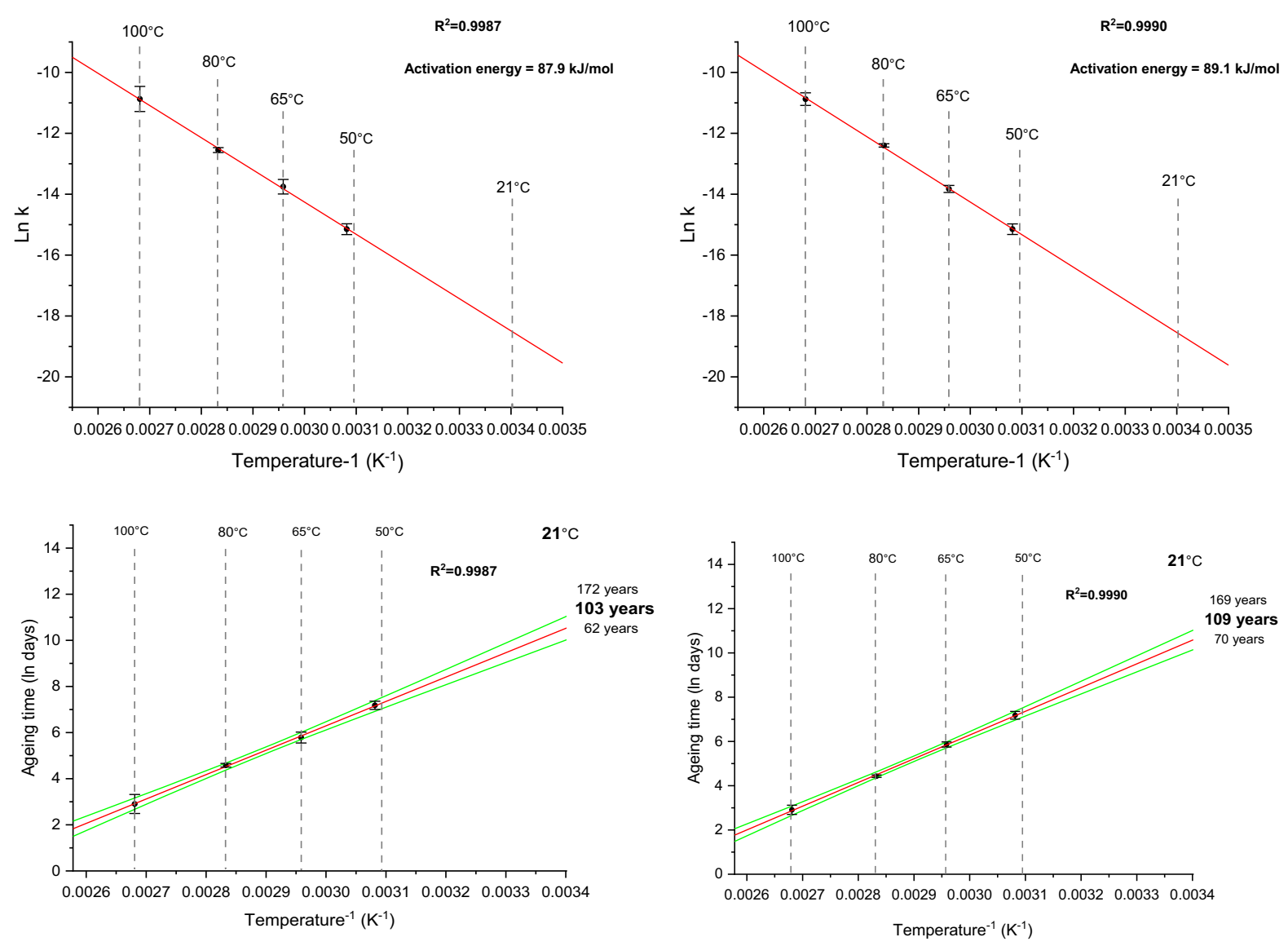

Fig. 5 Top: Arrhenius plot of Whatman No. 1 for cellulose depolymerization after correction of the rate of cellulose chain scission $\left(k^{\prime \prime}\right)$. Left: Period I, right: Period II. Bottom: Extrapolated period to reach the half-life DP of Whatman No. 1 at room

temperature $\left(21^{\circ} \mathrm{C}\right)$ after correction of the rate of cellulose chain scission $\left(k^{\prime \prime}\right)$. Left: Period I, right: Period II. Confidence interval: $95 \%$ 

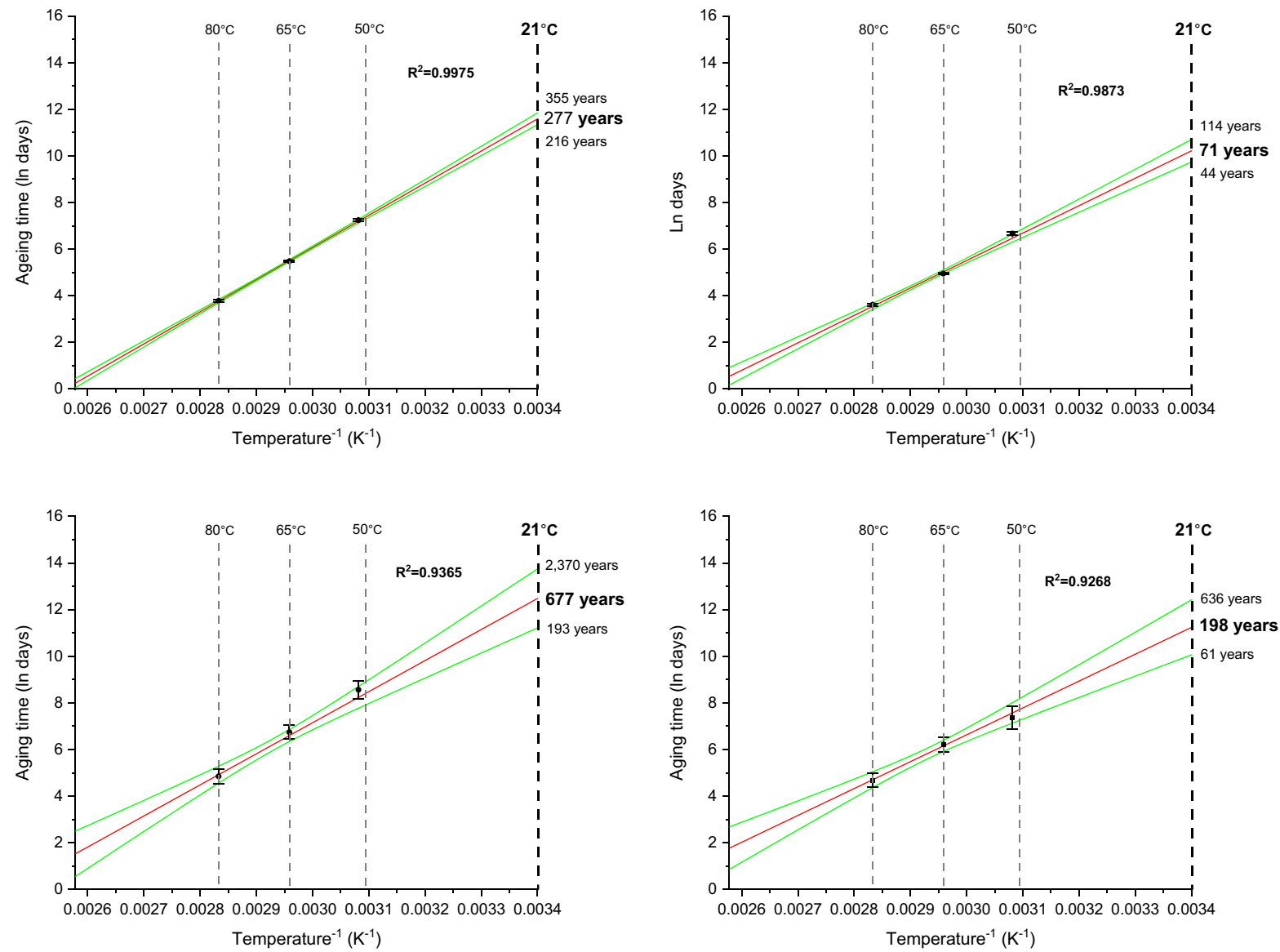

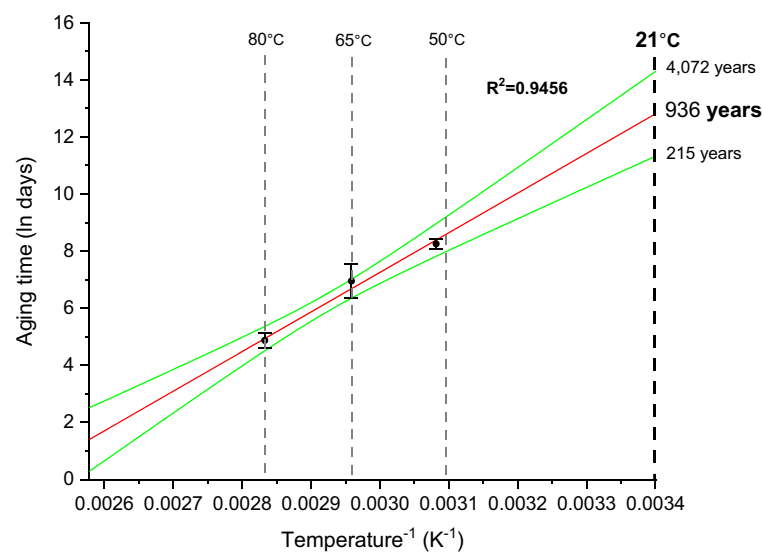

Fig. 6 Extrapolated period to reach the half-life DP of EN pulp (top), rag paper (middle), book paper (bottom) at room temperature $\left(21^{\circ} \mathrm{C}\right)$ before (left) and after (right) correction of

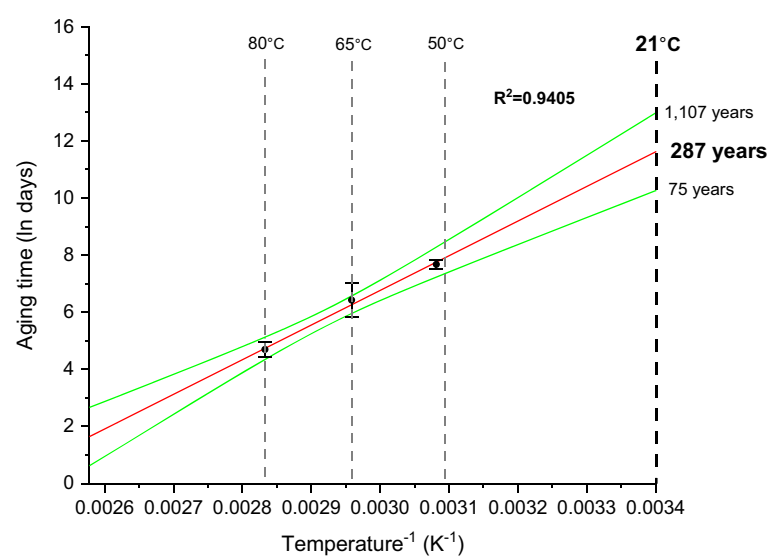

the rate of cellulose chain scission $\left(k^{\prime \prime}\right)$. Aging period: 15 days, $80{ }^{\circ} \mathrm{C}$; 85 days, $65^{\circ} \mathrm{C}$; and 203 days, $51.5^{\circ} \mathrm{C}$ ). Confidence interval: $95 \%$ 
Correction of the rate of cellulose chain scission and half-life DP

With hydrolysis and oxidation not influencing the content of water significantly we need to correct the $k$ value by taking the moisture content of the paper into account as described above (Table 5).

Based on Sebera's equation (Eq. 4), the $k$ value was corrected to $k^{\prime \prime}$ based on the ratio of the initial moisture content $\left(M_{i}, \mathrm{mg}\right)$ and average moisture content $\left(M_{A v}\right.$, $\mathrm{mg})(17)$ :

$k^{\prime \prime}=k \frac{M_{A v}}{M_{i}} \quad\left(\frac{k}{k^{\prime \prime}}=\frac{M_{i}}{M_{A v}}\right)$

The Arrhenius plot and half-life DP were recalculated using the corrected $k^{\prime \prime}$ (Table 6, Fig. 5). Unlike the $k$ value (and to a lesser extent also the corrected $k^{\prime}$ value), which had decreased with increasing aging time, the hydrolysis rate $k^{\prime \prime}$ remained constant regardless of the aging period (Table 6), which proved the validity of the remediation. Correcting the cellulose hydrolysis rate in this way also reduced activation energy by approximately $10 \%$ in both the short-term $(87.9 \mathrm{~kJ} / \mathrm{mol})$ and long-term aging periods $(89.1 \mathrm{~kJ} / \mathrm{mol})$, which resulted in a reduction of the half-life DP. The half-life DP results for the shortand long-term periods were 103 and 109 years, respectively, a difference of approximately $6 \%$. The presented correction based on the moisture conditions represents a significant improvement in aging methodology; it largely removes the dependency of the hydrolysis rate on the aging period. The thus corrected $k^{\prime \prime}$ values result in a constant cellulose hydrolysis rate (within the error of determination), irrespective of the aging time (Table 6 and Fig. 5), and also the predicted half-life values improve accordingly (Fig. 5 bottom).

The $k$ and $k$ " values obtained from Whatman No.1 were compared by applying them to different types of paper. The range of $95 \%$ confidence intervals were significantly improved. The longer an aging test takes, the more moisture can escape from the vials. This leads to a decrease in of $k$, resulting in an increase in the half-life DP. Although the $k$ " values are inevitably different depending on the type of paper, it can be seen that simply using the value of $k$ " obtained from Whatman No.1 can significantly improve the results (Fig. 6).

\section{Conclusions}

To improve the reliability of a standard method in paper conservation science, the so-called closed-vial aging, this study investigated the relationship between moisture leakage, a major source of error in this method, and the resulting rate of cellulose hydrolysis. Conventionally, the derived cellulose hydrolysis rate diminishes with increasing aging time due to progressive moisture leakage during aging, which results in strongly differing predictions as to the expected halflife of the sample, the main number of interest for conservators, librarians and archivists.

First, the degradation of cellulose (i.e., half-life DP) was evaluated using the Arrhenius and Ekenstam equation based on the traditional aging method in a closed vial. As expected, the difference in half-life DP intensified with increasing aging periods.

To minimize the error caused by moisture leakage, the rate of cellulose hydrolysis was corrected using the ratio of the average $\mathrm{RH}$ to the initial $\mathrm{RH}$ in the closed vial. As a result, the difference in half-life DP between the short- and long-term aging periods was reduced, however insufficiently as the difference in half-life DP still increased with longer aging periods. For further improvement, the rates of cellulose hydrolysis were corrected based on the moisture content of the paper itself rather than the average $\mathrm{RH}$ in the vial. As a result, the difference in the time to reach the half-life DP between the short- and long-term aging periods improved significantly from $24 \%$ before correction down to only $6 \%$ afterwards. This improvement was now independent of the aging time.

Although also the improved cellulose hydrolysis rate, corrected by the method presented in this study, can naturally not perfectly predict cellulose degradation during natural aging, it represents a valuable methodological improvement. It significantly enhances the meaningfulness and accuracy of data from accelerated degradation according to the closedvial protocol.

Acknowledgments This research was supported by the EU project MEMORI - Measurement, Effect Assessment and Mitigation of Pollutant Impact on Movable Cultural AssetsInnovative Research for Market Transfer, Grant agreement 265132 and by a grant from the National Research Foundation Korea, which was funded by the Korean government (MSIT) (NRF-2014R1A1A1007624). The authors would like to thank the Writing Center at Jeonbuk National University for its skilled 
proofreading services and Dr. Thomas Rosenau for fruitful discussions. Open access funding provided by University of Natural Resources and Life Sciences Vienna (BOKU).

Author contributions Formal analysis: M-JJ and AP; investigation: $\mathrm{M}-\mathrm{JJ}$ and $\mathrm{AP}$; data curation: $\mathrm{M}-\mathrm{JJ}$ and $\mathrm{AP}$; writing (original draft): M-JJ; writing (review and editing): AP; supervision: AP.

Funding Open access funding provided by University of Natural Resources and Life Sciences Vienna (BOKU).

\section{Declarations}

Conflict of interest The authors declare that they have no conflict of interest.

Open Access This article is licensed under a Creative Commons Attribution 4.0 International License, which permits use, sharing, adaptation, distribution and reproduction in any medium or format, as long as you give appropriate credit to the original author(s) and the source, provide a link to the Creative Commons licence, and indicate if changes were made. The images or other third party material in this article are included in the article's Creative Commons licence, unless indicated otherwise in a credit line to the material. If material is not included in the article's Creative Commons licence and your intended use is not permitted by statutory regulation or exceeds the permitted use, you will need to obtain permission directly from the copyright holder. To view a copy of this licence, visit http://creativecommons.org/licenses/by/4.0/.

\section{References}

Area M, Cheradame H (2011) Paper aging degradation: recent finding and research methods. BioResources 6(4):5307-5337

Arney J, Jacobs A (1979) Accelerated aging of paper: the relative importance of atmospheric oxidation. TAPPI 62(7):89-91

Banik G, Brückle I (2010) Principles of water absorption and desorption in cellulosic materials. Restaurator 31:164-177. https://doi.org/10.1515/rest.2010.012

Banik G, Brückle I (2011) Paper and water: a guide for conservators. Routledge, London

Becker M, Meyer F, Jeong M-J, Ahn K, Henniges U, Potthast A (2016) The museum in a test tube-adding a third dimension to the evaluation of the impact of volatile organic acids on paper. Polym Degrad Stab 130:181-199. https://doi.org/ 10.1016/j.polymdegradstab.2016.05.026

Choi K-H, Lee K, Lee J, Lee M, Ryu J (2019) Artificial aging characteristics of hydrophobic hanjis grafted by gaseous palmitoyl chloride. J Korea TAPPI 49(6):98-107. https:// doi.org/10.7584/JKTAPPI.2019.06.51.3.98

Coppola F, Brown N, Amicucci F, Strlič M, Modelli A (2020) Non-destructive collection survey of the historical Classense Library. Part II: conservation scenarios. Herit Sci. 8(89):1-10https://doi.org/10.1186/s40494-020-00430-y
Feber M, Havermans J, Cornelissen E (1998) The positive effects of air purification in the Dutch State Archives. Part I: experimental set up and air quality. Restaurator 19:212-223. https://doi.org/10.1515/rest.1998.19.4.212

Fenech A, Strlič M, Cigić IK, Levart A, Gibson LT, de Bruin G, Ntanos K, Kolar J, Cassar M (2010) Volatile aldehydes in libraries and archives. Atmos Environ 44(17):2067-2073

Havermans J (1995) Effects of air pollutants on the accelerated aging of cellulose-based materials. Restaurator 16:209-233. https://doi.org/10.1515/rest.1995.16.4.209

Henniges U, Prohaska T, Banik G, Potthast A (2006) A fluorescence labeling approach to assess the deterioration state of aged papers. Cellulose 13(4):421-428. https://doi.org/ 10.1007/s10570-005-9030-3

Jeong M-J, Dupont A-L, De la Rie E (2012) Degradation of cellulose at the wet-dry interface. I. Study of the depolymerization. Cellulose 19:1135-1147. https://doi.org/10. 1007/s10570-012-9722-4

Jeong M-J, Bogolitsyna A, Jo BM, Kang KY, Rosenau T, Potthast A (2014a) Deterioration of ancient Korean paper (hanji), treated with beeswax: a mechanistic study. Carbohydr Polym 101:1249-1254. https://doi.org/10.1016/j. carbpol.2013.10.033

Jeong M-J, Kang KY, Bacher M, Kim HJ, Jo BM, Potthast A (2014b) Deterioration of ancient cellulose paper, hanji: evaluation of paper permanence. Cellulose 21:4621-4632. https://doi.org/10.1007/s10570-014-0455-4

Kaminska E, Bégin P, Grattan D, Woods D, Bülow A (2001) ASTM/ISR research program on the effects of aging on printing and writing papers: accelerated aging test method development. Canadian Conservation Institute, West Conshohocken

Kontturi E, Meriluoto A, Penttilä P, Baccile N, Malho J-M, Potthast A, Rosenau T, Ruokolainen J, Serimaa R, Laine J, Sixta H (2016) Simultaneous degradation and crystallisation of cellulose by hydrogen chloride vapour. Angew Chem Int Ed Engl 55(46):14455-14458. https://doi.org/10. 1002/anie. 201606626

Ligterink F, di Pietro G (2018) The limited impact of acetic acid in archives and libraries. Herit Sci. https://doi.org/10.1186/ s40494-018-0225-y

Menart E, de Bruin G, Strlič M (2011) Dose-response functions for historic paper. Polym Degrad Stab 96:2029-2039. https://doi.org/10.1007/s10570-014-0374-4

Menart E, de Bruin G, Strlič M (2014) Effects of $\mathrm{NO}_{2}$ and acetic acid on the stability of historic paper. Cellulose 21:3701-3713. https://doi.org/10.1007/s10570-014-03744

Potthast A, Röhrling J, Rosenau T, Borgards A, Sixta H, Kosma P (2003) A novel method for the determination of carbonyl groups in cellulosics by fluorescence labelling. 3. Monitoring oxidative processes. Biomacromol 4(3):743-749. https://doi.org/10.1021/bm025759c

Potthast A, Rosenau T, Kosma P, Saariaho A-M, Vuorinen T (2005) On the nature of carbonyl groups in cellulosic pulps. Cellulose 12(1):43-50. https://doi.org/10.1023/B:CELL. $0000049347.01147 .3 \mathrm{~d}$

Potthast A, Henniges U, Banik G (2008) Iron gall ink-induced corrosion of cellulose: Aging, degradation and stabilization. Part 1: Model paper studies. Cellulose 15(6):849-859. https://doi.org/10.1007/s10570-008-9237-1 
Potthast A, Radosta S, Saake B, Lebioda S, Heinze T, Henniges U, Isogai A, Koschella A, Kosma P, Rosenau T, Schiehser S, Sixta H, Strlič M, Strobin G, Vorwerg W, Wetzel H (2015) Comparison testing of methods for gel permeation chromatography of cellulose: coming closer to a standard protocol. Cellulose 22(3):1591-1613. https://doi.org/10. 1007/s10570-015-0586-2

Röhrling J, Potthast A, Rosenau T, Lange T, Borgards A, Sixta H, Kosma P (2001) Synthesis and testing of a novel fluorescence label for carbonyls in carbohydrates and cellulosics. Synlett 5:682-684. https://doi.org/10.1055/s-200113363

Röhrling J, Potthast A, Rosenau T, Lange T, Ebner G, Sixta H, Kosma P (2002) A novel method for the determination of carbonyl groups in cellulosics by fluorescence labeling. 1 . Method development. Biomacromol 3:959-968. https:// doi.org/10.1021/bm020029q

Sawoszczuk T, Barański A, Łagan J, Łojewski T, Zięba K (2008) On the use of ASTM closed vessel tests in accelerated ageing research. J Cult Herit 9:401-411. https://doi. org/10.1016/j.culher.2007.10.010

Sebera K (1994) Isoperms: an environmental management tool. The Commission on Preservation and Access, Washington

Sequeira SO, Cabrita EJ, Macedo MF (2014) Fungal biodeterioration of paper: how are paper and book conservators dealing with it? An international survey. Restaurator 35:181-199. https://doi.org/10.1515/rest-2014-0005

Shahani C, Lee S, Hengemihle F, Harrison G, Song P, Sierra M, Ryan C, Weberg N (2001) Report on: Accelerated aging of paper: I. Chemical analysis of degradation products. II. Application of Arrhenius relationship. III. Proposal for a new accelerated aging test: ASTM research program into the effect of aging on printing and writing papers. Library of Congress, Washington

Son H-N, Ye J-H, Jang K-J, Jeong S-H (2017) Analysis of dryheat and humid-heat artificial aging characteristics of Hanji for restoration of paper cultural heritage. J Korea TAPPI 49(6):22-30. https://doi.org/10.7584/JKTAPPI.2017.12. 49.6 .22

Stamm AJ (1956) Thermal degradation of wood and cellulose. Ind Eng Chem 48(3):413-417. https://doi.org/10.1021/ ie51398a022

Strlič M, Kolar J, Kočar D, Drnovšek T, Šelih S, Susič R, Pihlar $\mathrm{B}$ (2004) What is the $\mathrm{pH}$ of alkaline paper? e-Preservation Sci 1:35-47
Strlič M, Cigić I, Možir A, Thickett D, De Bruin G, Kolar J et al (2010) Test for compatibility with organic heritage materials-a proposed procedure. e-Preservation Sci 7:78-86

Strlič M, Cigić I, Možir A, Bruin G, Kolar J, Cassar M (2011) The effect of volatile organic compounds and hypoxia on paper degradation. Polym Degrad Stabil 96:608-615. https://doi.org/10.1016/j.polymdegradstab.2010.12.017

Strlič M, Grossi CM, Dillon C, Bell N, Fouseki K, Brimblecombe P, Menart E, Ntanos K, Lindsay W, Thickett D, France F, de Bruin G (2015) Damage function for historic paper. Part II: wear and tear. Herit Sci. https://doi.org/10. 1186/s40494-015-0065-y

TAPPI test method T573 (2015) Accelerated temperature aging of printing and writing paper by dry oven exposure apparatus

Tétreault J, Dupont A-L, Bégin P, Paris S (2013) The impact of volatile compounds released by paper on cellulose degradation in ambient hygrothermal conditions. Polym Degrad Stabil 98:1827-1837. https://doi.org/10.1016/j. polymdegradstab.2013.05.017

Tétreault J, Bégin P, Paris-Lacombe S, Dupont AL (2019) Modelling considerations for the degradation of cellulosic paper. Cellulose 26(3):2013-2033. https://doi.org/10. 1007/s10570-018-2156-X

Zervos S (2010) Natural and accelerated ageing of cellulose and paper: a literature review. In: Cellulose-structure and properties, derivatives and industrial uses, Deprez T, Nova Science Publishers, New York, pp 155-203.

Zou X, Gurnagul N, Uesaka T (1994) Bouchard, J (1994) Accelerated aging of papers of pure cellulose: mechanism of cellulose degradation and paper embrittlement. Polym Degrad Stab 43(3):393-402. https://doi.org/10.1016/01413910(94)90011-6

Zou X, Uesaka T, Gurnagul N (1996a) Prediction of paper permanence by accelerated aging I. Kinetic analysis of the aging process. Cellulose 3:243-267. https://doi.org/10. 1007/BF02228805

Zou X, Uesaka T, Gurnagul N (1996b) Prediction of paper permanence by accelerated aging II. Comparison of the predictions with natural aging results. Cellulose 3:269-279. https://doi.org/10.1007/BF02228806

Publisher's Note Springer Nature remains neutral with regard to jurisdictional claims in published maps and institutional affiliations. 